\title{
Identification of the paraproteins and clinical significance of more than one paraprotein in serum of 56 patients
}

\author{
MARTIN E. GORE, PAMELA G. RICHES ${ }^{1}$, AND J. KOHN \\ From the Supraregional Protein Reference Laboratory, Putney Hospital, London SW15, UK
}

SUMMARY Sera from 56 patients with more than one paraprotein were investigated for immunoglobin class and light chain type of each paraprotein. The patients were divided into two groups according to the diagnosis, that is, myeloma and macroglobulinaemia or others. The frequency of combinations of paraproteins was considered in the whole series and in the two groups. The laboratory and clinical findings were analysed to investigate the diagnostic and prognostic significance of more than one paraprotein in a serum. It is concluded that a lower percentage of patients with more than one paraprotein can definitely be shown to have myeloma than might be expected from studies on monoclonal paraproteinaemia, that patients having IgA paraproteins in the serum had the poorest prognosis, and that paraproteins with lambda light chains were more likely to be associated with myeloma or macroglobulinaemia.

A discriminant analysis of ESR and total paraprotein levels in the two groups of patients showed that combinations of the two parameters were not more effective at distinguishing the groups than the ESR alone.

Over the years an increasing number of patients with paraproteinaemia have been recognised as having more than one monoclonal band on serum electrophoresis. This is probably due to improved electrophoretic techniques, increased awareness that such a situation exists, and an increase in the number of patients having their serum examined by electrophoresis.

The finding of more than one paraprotein is commonly called biclonal or oligoclonal paraproteinaemia, depending on the number of bands seen. However, there are a number of cases where the multiple bands do not necessarily come from different clones of cells:

(1) post-synthetic alterations, deamination, polymerisation (especially IgA), complexing, breakdown with denaturation; or

(2) parent immunoglobulin plus fragment or Bence Jones protein in addition to a major paraprotein band.

${ }^{1}$ Present address: Protein Reference Unit, Department of Chemical Pathology, Westminster Hospital, 17 Page Street, London SW1P 2AR

Received for publication 28 September 1978
Immunofluorescence studies on the bone marrow of patients showing more than one paraprotein have indicated in a number of cases distinct plasma cell populations synthesising each of the paraproteins (Rosen et al., 1967; Dittmar et al., 1968). In one instance, however, both paraproteins were simultaneously synthesised by the same plasma cells (Costea et al., 1967). Other studies on the individual immunoglobulins in biclonal paraproteinaemia have indicated common antibody combining sites (Fudenberg et al., 1971), identical variable regions of the heavy chain and identical light chains (Rudders et al., 1973), also suggesting a single clonal origin for two different paraproteins.

In a recent study of 16 patients with double paraproteinaemia (van Camp et al., 1978) three situations could be identified from the results of immunofluorescent studies of bone marrow samples. These were:

(1) different cell populations synthesising each paraprotein (6 patients);

(2) single cell population synthesising both paraproteins ( 3 patients); and

(3) evidence for proliferation of precursor cells 'switching' from one immunoglobulin class to 
another, leading to the formation of two clones (9 patients).

The concept of multiclonicity, therefore, does not always apply, and we suggest the term 'multiband paraproteinaemia' to describe the finding of more than one paraprotein band by zone electrophoresis. The purpose of our study was to establish the diagnostic and prognostic significance of multiband paraproteinaemia.

It must be emphasised that this study was retrospective and suffers from all the usual problems of loss of relevant clinical and laboratory data with the passage of time.

\section{Material and methods}

\section{PATIENTS}

The records of the Protein Reference Unit, Putney Hospital over a period of two years were examined, and any patient with two or more paraprotein bands in the serum and for whom clinical information was available was included.

\section{CLINICAL STATE OF PATIENTS}

The diagnosis and clinical state of the patient were obtained directly from the hospital notes or from summaries prepared by the referring hospital. Likewise, the routine haematology, biochemistry, and bone marrow reports were obtained from the referring hospitals.

\section{METHODS}

All immunological investigations were performed at the Protein Unit. Paraprotein bands were first detected by cellulose acetate membrane electrophoresis, and then classified and typed by a combination of immunoelectrophoresis (Grabar and Williams, 1953), immunotransfer (Kohn, 1976), and immunofixation (Kohn and Riches, 1978). The paraproteins were quantitated by scanning Ponceaustained electrophoresis strips.

\section{Statistical methods}

Discriminant analysis (Fisher, 1938; Rao, 1952; Armitage, 1971) was used to investigate whether the differences in ESR and paraprotein values between patients with myeloma or macroglobulinaemia and those with other diagnoses were large enough to be of diagnostic value.

Discriminant functions were constructed using ESR and paraprotein values, singly or in combination. For each discriminant function, the generalised distance, $\Delta$, between the two groups was calculated, and its significance was tested using Hotelling's
$\mathrm{T}^{2}$ statistic, which is a generalisation of Student's $t$ for more than one variable.

For each discriminant function, the proportion of individuals expected to be misclassified was estimated (Hills, 1966; Lachenbruch, 1975).

\section{Results}

The incidence of multiband paraproteinaemia over the two-year period of the study was about $11 \%$ (108 from a total of approximately 1000 patients with paraproteinaemia). Of the patients with multiband paraproteinaemia, 52 were excluded due to insufficient clinical records or non-availability of serum to check previous electrophoretic findings and paraprotein identification. The remaining 56 patients had sufficient data to be included in the study. The nature of the paraprotein bands is shown in Table 1a. The total number of bands in each category is not shown.

Table 1a Identity of paraprotein bands in 56 patients showing multiband paraproteinaemia

\begin{tabular}{ll}
\hline Identity of paraprotein bands & Number $(\%)$ of patients \\
\hline All bands IgA* & $19(33.9)$ \\
All bands IgG* & $12(21 \cdot 4)$ \\
All bands IgM & $6(10.7)$ \\
All bands BJ & $2(3.6)$ \\
IgG and IgM* & $6(10.7)$ \\
IgA and IgG & $3(5 \cdot 4)$ \\
IgG and IgD & $1(1.8)$ \\
IgA and BJ* & $3(5.4)$ \\
IgG and BJ & $4(7 \cdot 1)$ \\
\hline
\end{tabular}

*Includes patients with three or four bands

In 11 out of the 56 patients there were more than two paraproteins present. The nature of these bands is shown in Table 1b. In Table 1a and in all subsequent analyses patients with three and four bands are considered together with those with just two paraproteins, all under the definition of multiband paraproteinaemia.

Table 1b Identity of paraproteins in patients with more than two paraproteins

\begin{tabular}{ll}
\hline 3 bands & 4 bands \\
\hline IgAL + IgAL + IgAL & BJK + BJK + IgGK + IgGK \\
IgAK + IgAK + IgAK(2) & BJK + BJK + IgAK + IgAK \\
IgAK + IgAK + BJK & IgGK + IgGK + IgMK + IgMK \\
IgAK + IgGK + IgGK & \\
IgAK + IgGK + IgML & \\
IgAK + IgGK + IgMK(2) & \\
\hline
\end{tabular}

In a review of the recent literature on biclonal paraproteinaemia, the observed incidence of the major immunoglobulin classes, viz, $\operatorname{Ig} \mathbf{A}+\operatorname{Ig} \mathbf{A}$, 
IgG + IgG, IgG + IgM, IgA + IgG, and IgM + IgM, was compared to a theoretically calculated incidence (Bouvet et al., 1975). Table 2 shows this comparison as well as the incidence of these categories in our own study and in another recent survey (Kövary et al., 1977).

Table 2 Distribution of major immunoglobulin classes in multiband paraproteinaemia

\begin{tabular}{|c|c|c|c|c|}
\hline \multirow{3}{*}{$\begin{array}{l}\text { Immunoglobulin } \\
\text { class }\end{array}$} & \multicolumn{4}{|l|}{ Series } \\
\hline & \multirow[t]{2}{*}{$\begin{array}{l}\text { Present } \\
\text { (56) }\end{array}$} & \multicolumn{2}{|c|}{$\begin{array}{l}\text { Bouvet et al. } \\
\text { (1975) (141) }\end{array}$} & \multirow{2}{*}{$\begin{array}{l}\text { Kövary et al. } \\
(1977)(24) \\
\% \text { of total }\end{array}$} \\
\hline & & $\begin{array}{l}\text { Observed } \\
\% \text { of total }\end{array}$ & $\begin{array}{l}\text { Theoretical } \\
\% \text { of total }\end{array}$ & \\
\hline $\mathbf{G}+\mathbf{G}$ & $26 \cdot 1$ & $26 \cdot 4$ & $44 \cdot 7$ & 32 \\
\hline $\mathbf{A}+\mathbf{A}$ & $41 \cdot 3$ & 1.6 & $4 \cdot 3$ & - \\
\hline $\mathbf{M}+\mathbf{M}$ & $13 \cdot 0$ & 8.5 & $2 \cdot 8$ & - \\
\hline $\mathbf{G}+\mathbf{M}$ & 13.0 & $26 \cdot 4$ & $20 \cdot 8$ & 18 \\
\hline $\mathbf{A}+\mathbf{G}$ & 6.5 & $35 \cdot 7$ & 26.0 & 50 \\
\hline $\mathbf{M}+\mathbf{A}$ & 0 & $9 \cdot 3$ & 6.9 & - \\
\hline
\end{tabular}

Figures in parentheses refer to total number of patients in each series

Our 56 patients were divided into two groups: those with a diagnosis of myeloma or macroglobulinaemia, and those with other diagnoses (Table 3). The nature and the percentage incidence of the paraprotein bands within these two groups are shown in the Figure. In the present series, IgA multiband paraproteinaemia was the commonest finding both overall and in the myeloma group. This is in sharp contrast to previous findings (Bouvet et al., 1975).

Table 3 Diagnosis in patients with conditions other than myeloma or macroglobulinaemia (ie, non-myeloma group)

\begin{tabular}{ll}
\hline Number of patients & Diagnosis \\
\hline 6 & $\begin{array}{l}\text { Neurological disease } \\
\text { Malignant disease (3 lymphoma; 1 carcinoma } \\
\text { stomach) } \\
\text { Others } \\
\text { Diabetes mellitus (2 patients) } \\
\text { pericarditis, influenza, septicaemia, hyper- } \\
\text { tension (2 patients), coeliac disease, thyrotoxi- } \\
\text { cosis, haemolytic anaemia, PUO, osteogenesis } \\
\text { imperfecta, alcoholism }\end{array}$ \\
\hline
\end{tabular}

In our series, about $60 \%$ of multiband paraproteinaemias were associated with myeloma or macroglobulinaemia. In the myeloma group, six of the total of 33 patients had three or more paraproteins, and in the non-myeloma group, five of a total of 23. We found no evidence that multiband myeloma has a worse prognosis than myeloma associated with a single band.

The light chain typing in the two groups is shown in Table 4. In the myeloma group the distribution

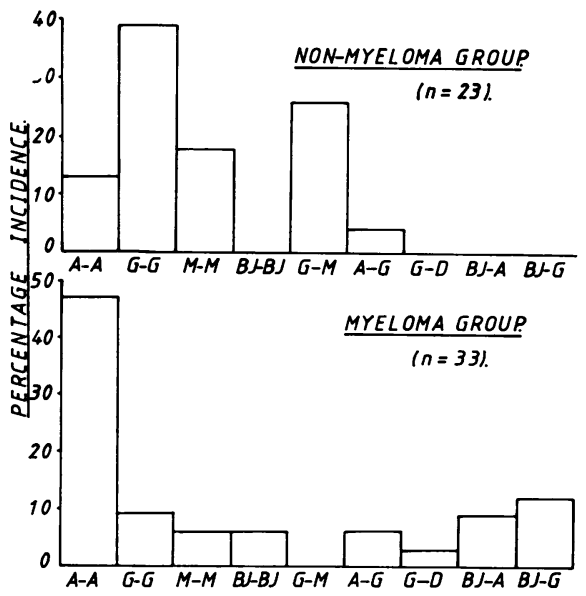

Figure Percentage incidence of various paraprotein combinations in multiband paraproteinaemia in the two groups of patients studied, ie, 33 classified as myeloma and 23 with diagnoses other than myeloma.

Table 4 Percentage incidence of light chain types in multiband paraproteinaemia

\begin{tabular}{llll}
\hline Light chain & \multirow{2}{*}{ Total } & Group & \\
\cline { 3 - 4 } & & $\begin{array}{l}\text { Myeloma and } \\
\text { macroglobulinaemia }\end{array}$ & Non-myeloma \\
\hline Kappa & 77 & 69 & 90 \\
Lambda & 22 & 31 & 10 \\
\hline
\end{tabular}

of kappa and lambda light chains was the same as in normal immunoglobulins $(68.9 \%$ and $31 \cdot 1 \%)$. Although there was no correlation between survival time and light chain type, kappa light chains were found very much more frequently in the non-myeloma group than were lambda light chains.

In 52 out of 56 patients it was found that, in any one patient, the paraprotein bands were all of the same light chain type. In the remaining four patients, paraproteins of both kappa and lambda light chain type were found. These four patients had paraproteins identified as follows: $\operatorname{IgG}^{\prime} \mathrm{L}^{\prime}+\operatorname{IgA}^{\prime} \mathrm{K}^{\prime}$, $I^{\prime g M} M^{\prime} K^{\prime}+\operatorname{IgG}^{\prime} L^{\prime}, I^{\prime} G^{\prime} K^{\prime}+\operatorname{Ig} A^{\prime} L^{\prime}$, and $\operatorname{IgG}{ }^{\prime} K^{\prime}+$ IgG'$^{\prime} K^{\prime}+I^{\prime} M^{\prime} L '$ '. In none of these last four patients was there clear evidence of myeloma.

The survival, from the time of presentation, was studied in 20 patients with a firm diagnosis of myeloma. Eight were dead within one year, seven of these had exclusively IgA paraproteins, and out of these seven only one survived more than six months.

The parameters usually measured during the evaluation of the clinical significance of paraproteinaemia are haemoglobin, ESR, urea, albumin, calcium, total amount of paraprotein, immuno- 
globulin levels, and Bence Jones proteinuria. All these were assessed in our study with reference to diagnosis and survival. Anaemia, high ESR, high paraprotein levels, immunosuppression, and the presence of Bence Jones proteinuria were associated with a diagnosis of myeloma. Likewise, correlation with survival in this group followed the same pattern as that seen in myeloma in general, for example, low albumin and/or a high urea was related to short survival time.

A discriminant analysis was carried out to determine significant combinations of the ESR and total paraprotein level which could distinguish the myeloma from the non-myeloma patients.

For each combination of variables used to construct a discriminant function, Table 5 shows the generalised distance $\Delta$ between the two groups, the probability level given by the $T^{2}$ test for the significance of $\Delta$, and Lachenbruch's estimate of the misclassification rate, which classified each individual using a variant of the discriminant function which was constructed using only the values from the other individuals. This avoids the bias that would result from testing a discriminant function on the individuals from which it was constructed.

Table 5 Discriminant analysis of total paraprotein, $E S R$, and combinations of paraprotein and ESR used to classify patients with myeloma or macroglobulinaemia (14 patients) from those with other diagnosis (11 patients)

\begin{tabular}{clll}
\hline Variable & $\Delta$ & $P$ & $\begin{array}{l}\text { Misclassified } \\
\text { (out of 25\%) }\end{array}$ \\
\hline 1 & $3 \cdot 26$ & $<0.1 \%$ & 2 \\
2 & $1 \cdot 73$ & $<0.1 \%$ & 4 \\
3 & $2 \cdot 14$ & $<0.1 \%$ & 4 \\
1,2 & $3 \cdot 26$ & $<0.1 \%$ & 2 \\
2,3 & $2 \cdot 20$ & $<0.1 \%$ & 4 \\
1,3 & $3 \cdot 27$ & $<0.1 \%$ & 2 \\
$1,2,3$ & $3 \cdot 29$ & $<0.1 \%$ & 2 \\
\hline
\end{tabular}

Variable 1 = ESR

2 = Paraprotein

$3=$ Product of ESR and paraprotein

Although a combination of the ESR and paraprotein level was more effective in distinguishing between these two groups than the paraprotein level alone, it was not statistically better than the ESR alone.

\section{Discussion}

The percentage incidence of the different classes of paraproteins in our study differs markedly from that found in other areas (Bouvet et al., 1975; Kövary et al., 1977). The main reason for this is possibly that there was no attempt to select any of our patients; that is, we included any patient with more than one band in the serum without regard to the clonal origin of the paraproteins. It is probable that other authors have excluded a considerable number of IgA paraproteins because of the frequency of polymerisation that is known to occur with these paraproteins. We also included patients who had Bence Jones in the serum in addition to the major paraprotein band. This group of patients was excluded in one other series (Bouvet et al., 1975).

It is of particular interest that, of the six patients who suffered from peripheral neuropathy, five had at least one IgM band but no evidence of myeloma or Waldenström's macroglobulinaemia.

Four patients had both kappa and lambda light chains on the different paraproteins in their sera, indicating true biclonicity. A rather surprising finding was that none of these patients showed any evidence of malignancy.

Our main objective was to assess the significance clinically of both the presence of multiband paraproteins and their class and type. The main conclusions are, firstly, that there was a lower percentage of patients with a definite diagnosis of myeloma than might be expected in a comparable group with single band paraproteinaemia (Hobbs, 1971). However, due to the short time scale of the study, it was impossible to be sure that some of the non-myeloma patients would not develop myeloma at a later stage. Secondly, patients with IgA multibands are more likely than patients with multibands of other classes to have myeloma. Also those patients with IgA multibands can be expected to have very short survival times. Thirdly, the unexpectedly low percentage of paraproteins of the lambda light chain type found in the non-myeloma group suggest that these are more likely to be associated with myeloma or macroglobulinaemia.

Finally, it must be stressed that our study was done on the material of a reference laboratory and was, therefore, highly selective. However, it is virtually impossible to get such a large number of patients with both benign and myeloma-associated multiband paraproteinaemia from any other source.

We thank Mr James Hunt, Medical Computer Department, Westminster Hospital Medical School for all his help with the statistical evaluation of the data.

\section{References}

Armitage, P. (1971). Statistical Methods in Medical Research. Blackwell, Oxford and Edinburgh.

Bouvet, J. P., Feingold, J., Oriol, R., and Liacopoulos, P. (1975). Statistical study on double paraproteinemias: 
evidence for a common cellular origin of both myeloma globulins. Biomedicine, 22, 517-523.

Costea, N., Yakulis, V. J., Libnoch, J. A., Pilz, C. G., and Heller, P. (1967). Two myeloma globulins (IgG and $\operatorname{IgA})$ in one subject and one cell line. American Journal of Medicine, 42, 630-635.

Dittmar, K., Kochwa, S., Zucker-Franklin, D., and Wasserman, L. R. (1968). Coexistence of polycythemia vera and biclonal gammopathy (gamma GK and gamma AL) with two Bence Jones proteins (BJK and BJL). Blood, 31, 81-92.

Fisher, R. A. (1938). Statistical utilization of multiple measurements. Annals of Eugenics, 8, 376-386.

Fudenberg, H. H., Wang, A. C., Pink, J. R. L., and Levin, A. S. (1971). Studies of an unusual biclonal gammopathy. Annals of the New York Academy of Sciences, 190, 501-506.

Grabar, P., and Williams, C. A. (1953). Méthode permettant l'étude conjugée des proprietés électrophorétiques et immunochimiques d'un mélange de protéines: application au sérum sanguin. Biochimica et Biophysica Acta, 10, 193-194.

Hills, M. (1966). Allocation rules and their error rates. Journal of the Royal Statistical Society, B, 28, 1-20.

Hobbs, J. R. (1971). Immunoglobulins in clinical chemistry. Advances in Clinical Chemistry, 14, 219-317.

Kohn, J. (1976). Cellulose acetate immuno-electrophoresis. Chromatographic and Electrophoretic Techniques, Volume II, edited by Ivor Smith, 4th edition, pp. 120-126. Heinemann, London.
Kohn, J., and Riches, P. G. (1978). A cellulose acetate immunofixation technique. Journal of Immunological Methods, 20, 325-331.

Kövary, P. M., Janning, G., and Weyer, F. G. (1977). Vorkommen von Paraproteinamien. Laboratoriumsmedizin, 3/4, 58-60.

Lachenbruch, P. A. (1975). Discriminant Analysis. Hafner Press, New York. Collier Macmillan, London.

Rao, C. R. (1952). Advanced Statistical Methods in Biometric Research. Wiley, New York. Chapman and Hall, London.

Rosen, B. J., Smith, T. W., and Bloch, K. J. (1967). Multiple myeloma associated with two serum $\mathbf{M}$ components, $\gamma \mathrm{G}$ type $\mathrm{K}$ and $\gamma \mathrm{A}$ type L. New England Journal of Medicine, 277, 902-907.

Rudders, R. A., Yakulis, V., and Heller, P. (1973). Production of both IgG type lambda and IgA type lambda myeloma proteins by a single plasma cell line. American Journal of Medicine, 55, 215-221.

van Camp, B. G. K., Shuit, H. R. E., Hijmans, W., and Radl, J. (1978). The cellular basis of double paraproteinaemia in man. Clinical Immunology and Immunopathology, 9, 111-119.

Requests for reprints to: Dr P. Riches, Protein Reference Unit, Department of Chemical Pathology, Westminster Hospital, 17 Page Street, London SW1P 2AR. 